\title{
BIOANALYTICAL METHOD DEVELOPMENT AND VALIDATION OF ENTRECTINIB IN RAT PLASMA BY LIQUID CHROMATOGRAPHY-TANDEM MASS SPECTROMETRY
}

\author{
PRAVALLIKA KE*, PRAMEELA RANI A, RATNA KUMAR M
}

Department of pharmaceutical analysis, University College of Pharmaceutical Sciences, Acharya Nagarjuna University, Andhra Pradesh, India. Email: elvina2108@gmail.com

Received: 10 July 2020, Revised and Accepted: 22 September 2020

\section{ABSTRACT}

Objective: The objective of the study was to develop and validate the bioanalytical liquid chromatography-mass spectrometry (LCMS/MS) method for the estimation of entrectinib in bulk and pharmaceutical drugs in rat plasma.

Methods: Chromatographic separation of entrectinib with $\mathrm{D}_{4}$-entrectinib as internal standard (IS) was achieved using Waters Alliance highperformance liquid chromatography system, quaternary gradient pump of e 2695 using Luna, $250 \times 4.6 \mathrm{~mm}$, $5 \mu \mathrm{m}$ column and the mobile phase containing $0.1 \%$ formic acid and acetonitrile (ACN) within the ratio of 70:30\% v/v. The flow was $1.0 \mathrm{ml} / \mathrm{min}$; detection was carried out by absorption at $294 \mathrm{~nm}$ using a photodiode array detector at ambient temperature.

Results: The peak of entrectinib was eluted at retention times of $5.225 \mathrm{~min}$. The multiple reaction monitoring was $560.6 / 475.1$ (m/z) for entrectinib and $580.6 / 496.3(\mathrm{~m} / \mathrm{z})$ for IS entrectinib $\left(\mathrm{D}_{4}\right)$. The linearity range was $1-20 \mathrm{ng} / \mathrm{ml}$ with a regression coefficient of $0.999 . \%$ relative standard deviation of peak areas of all measurements was found to be $<2.0$ which complies with acceptance criteria.

Conclusion: The method was successfully validated and it had been found to be within limits for accuracy, precision, and linearity and it is stable under analytical conditions used.

Keywords: Liquid chromatography-mass spectrometry, Entrectinib, $\mathrm{D}_{4}$ - entrectinib.

(C) 2020 The Authors. Published by Innovare Academic Sciences Pvt Ltd. This is an open access article under the CC BY license (http://creativecommons. org/licenses/by/4. 0/) DOI: http://dx.doi.org/10.22159/ajpcr.2020.v13i11.39005

\section{INTRODUCTION}

Bioanalytical methods are used for the qualitative and quantitative analysis of drug substances in biological fluids (mainly plasma, serum, and urine) or tissue [1]. Bioanalytical methods are essential for bioavailability and bioequivalence studies. IUPAC name of entrectinib $N$-[5-(3,5-Difluorobenzyl)-1H-indazol-3-yl]-4-(4-methyl-1piperazinyl)-2- weight is $560.64 \mathrm{~g} / \mathrm{mol}$ and the molecular formula is $\mathrm{C}_{31} \mathrm{H}_{34} \mathrm{~F}_{2} \mathrm{~N}_{6} \mathrm{O}_{2}$. Entrectinib (INN, trade name Rozlytrek previously known as RXDX-101 and NMS-E628) is an anti-cancer drug used to treat ROS1positive non-small cell lung cancer and NTRK fusion-positive solid tumors $[2,3]$.

Entrectinib is a tyrosine kinase inhibitor; hence, it acts on several receptors. It acts as an adenosine triphosphate competitor and inhibits tropomyosin receptor tyrosine kinases (TRK) TRKA, TRKB, and TRKC, and also as proto-oncogene tyrosine-protein kinase ROS1 and anaplastic lymphoma kinase (ALK). TRK receptors produce cell proliferation through downstream signaling through the mitogenactivated protein kinase, phosphoinositide 3-kinase, and phospholipase C- $\gamma$. ALK produces similar signaling with the addition of downstream JAK/STAT activation. Inhibition of those pathways suppresses neoplastic cell proliferation and shifts the balance in favor of apoptosis, resulting in shrinking of tumor volume. Literature survey revealed that there is no analytical methods have been reported individually or in combination with other drugs. This study describes that a validated liquid chromatography-mass spectrometry (LC-MS)/MS method was developed for entrectinib in rat plasma along with stability studies.

\section{METHODS}

Chemicals and reagents

Entrectinib and internal standard (IS) (entrectinib $\mathrm{D}_{4}$ ) was procured from Gland Pharma PVT LTD, Hyderabad, India. Acetonitrile (ACN) of
LCMS grade was purchased from Rankem. Methanol and formic acid of LCMS grade from MERK. Water was from Milli Q System and plasma from local suppliers.

\section{Instrumentation}

Chromatographic separation of entrectinib was achieved on Waters Alliance-e2695 using Luna, $250 \times 4.6 \mathrm{~mm}, 5 \mu \mathrm{m}$ column and the mobile phase containing $0.1 \%$ formic acid and ACN in the ratio of $70: 30 \%$ $\mathrm{v} / \mathrm{v}$. The flow rate was $1.0 \mathrm{ml} / \mathrm{min}$. An injection volume was $10 \mu \mathrm{l}$ and the column temperature was $30^{\circ} \mathrm{C}$. The runtime was $10.0 \mathrm{~min}$. The LC-MS/MS consists of SCIEX QTRAP 5500 triple quadrupole mass spectrometer equipped with electrospray ionization (ESI) with an automatic sample injector. The mass spectrometer was operated in positive ESI mode. The drying gas temperature was $120-150^{\circ} \mathrm{C}$ and the Dwell time was $1 \mathrm{~s}$. Quantification was performed using multiple reaction monitoring (MRM) of the transitions.

\section{Preparation of standards and quality control (QC) samples}

The stock solution of entrectinib used during LCMS method development stage was prepared by dissolving the accurately weighted standard compound in ACN. Concentration of entrectinib standard solution was $0.5 \mathrm{mg} / \mathrm{ml}$, appropriate dilutions with the mobile phase were made from the stock solution to prepare the working standard solutions for method development, calibration curve, and QC samples. Working standard solution of entrectinib and IS $\left(D_{4}\right)$ was prepared in diluents (mobile phase) to get both have a concentration of $10 \mathrm{ng} / \mathrm{ml}$. Calibration curve was prepared by spiking appropriate amounts of working solution into the blank plasma to get final concentrations of $1,2.5,5,7.5,10,12.5,15$, and $20 \mathrm{ng} / \mathrm{ml}$ for the entrectinib. The calibration curve was prepared by plotting the peak area ratio of the transition pair of entrectinib to that of IS against the nominal concentration of calibration standards. 
The purpose of QC standards (QC) are to assess the performance of the assay procedure. It also covers the whole range of the calibration line. It must also cover the whole range of the calibration line. Low QC (LQC), that is, 3 times of lower limit of QC (LLOQ), mid QC (MQC), that is, $100 \%$ or near about of highest calibration point, high QC (HQC), that is, 150\% or near about of highest calibration point.

\section{Extraction procedure}

Simple liquid extraction is done. To a glass tube containing200 $\mu \mathrm{l}$ of blank plasma to this add $300 \mu \mathrm{l}$ of ACN, add $500 \mu \mathrm{l}$ of entrectinib of $10 \mathrm{ng} / \mathrm{ml}$ and IS of $10 \mathrm{ng} / \mathrm{ml}$. Finally, add 500 of diluent. The solution was mixed on a vortex mixer for approximately 5 min then centrifuges it for $20 \mathrm{~min}$ at $5000 \mathrm{rpm}$. Collect the $2 \mathrm{ml}$ supernatantant, these were directly injected into LC-MS/MS column.

\section{Assay validation}

The LCMS method was validated to satisfy the acceptance criteria of industrial guidance for the bioanalytical method validation [4], Food and Drug Administration of the United States, 2001 [5].

\section{LOD and LOQ}

LOD and LOQ were separately determined by the calibration curve method. LOD and LOQ of the compound were determined by injecting progressively lower concentrations of standard solutions using the developed LCMS method. The LOD concentrations for entrectinib are 0.10 $\mu \mathrm{g} / \mathrm{ml}$ and their $\mathrm{s} / \mathrm{n}$ values are 5 . The LOQ concentration for entrectinib is $1.0 \mu \mathrm{g} / \mathrm{ml}$; their $\mathrm{s} / \mathrm{n}$ values are 26 . The results are shown in Table 1 .

\section{Validation of developed bioanalytical LCMS method for entrectinib} System suitability

It is used to indicate whether the instrument in use is functioning properly or not and to give the green light to proceed with the assaying of the next batch of samples. System suitability samples were included at the start, middle, and end of each batch of samples. The final concentration of the system suitability samples was made up to contain $10 \mathrm{ng} / \mathrm{ml}$ entrectinib and $10 \mathrm{ng} / \mathrm{ml}$ IS in mobile phase. Relative standard deviation (RSD) \% of peak area and retention time (RT) for entrectinib and IS for six consecutive injections were checked to see whether they were below $2 \%$ and $5 \%$, respectively. The results are shown in Table 2 .

\section{Stability of stock solution}

An aqueous stock solution containing $10 \mathrm{ng} / \mathrm{ml}$ entrectinib and $10 \mathrm{ng} / \mathrm{ml}$ IS was prepared in diluent. The solution was divided into three containers, the first one stored at room temperature, the second one stored at deep freezer, and the last one stored at $-20^{\circ} \mathrm{C}$ (assumed stable as a freshly prepared solution). The solutions of drug and IS from

Table 1: LOD and LOQ data for entrectinib

\begin{tabular}{llllll}
\hline Name & LOD & & & LOQ & \\
\cline { 2 - 3 } \cline { 5 - 6 } & $\begin{array}{l}\text { Concentration } \\
(\mathbf{n g} / \mathbf{m l})\end{array}$ & $\mathbf{s} / \mathbf{n}$ & & $\begin{array}{l}\text { Concentration } \\
(\mathbf{n g} / \mathbf{m l})\end{array}$ & $\mathbf{s} / \mathbf{n}$ \\
\hline Entrectinib & 0.01 & 5 & & 0.1 & 26 \\
\hline
\end{tabular}

each storage conditions taken out at predetermined time intervals $(0,12$, and $24 \mathrm{~h})$ and were injected onto the LCMS. The peak area from the chromatogram of each sample was compared with that of freshly prepared samples. The results are shown in Table 2

\section{Calibration curve}

An 8-point calibration curve was prepared by spiking appropriate amounts of working solution into the blank plasma to get final concentrations of $1,2.5,5,7.5,10,12.5,15$, and $20 \mathrm{ng} / \mathrm{ml}$ for the entrectinib. The calibration curve represented in Fig. 2 was prepared by plotting the peak area ratio of the transition pair of entrectinib to that of IS against the nominal concentration of calibration standards. The results were fitted to linear regression analysis

\section{RESULTS AND DISCUSSION}

In the present study, LC-MS/MS assay was developed for positive ionization which was evaluated, and therefore, the full scan mass spectrum of entrectinib and IS in the positive MRM is presented in Figs. 3 and 4. Finally, the reliability of the method was assessed on the basis of linearity, accuracy, precision, sensitivity, selectivity, and recovery studies.

\section{Accuracy and precision}

Accuracy and precision should be assessed by analyzing a minimum of three validation batches, including both intra- and inter-day runs. Both within and between run accuracy and precision should be assessed. Each validation batch must comprise a minimum of six to eight non-zero calibration standards, one standard blank (matrix blank) and standard zero (matrix blank with IS) and six replicates of QC standards at each limit of quantification (LOQ) (LOQQC), low (LQC), middle (MQC), and high (HQC) levels [6-8]. Acceptance criteria should be between and within batch CV for low, middle, and HQC levels should be $\leq 15 \%$ and for the LOQQC level should be $\leq 20 \%$. The results are shown in Table 3 .

\section{Specificity and selectivity}

Selectivity or specificity should be evaluated to assess the interference at the RT of the analyte and IS with method conditions shown in Figs. 5-7 [9]. At least six lots of blank matrix should be processed and after analysis, spike six LOQ samples in the least interference blank and analyzed. For all the chromatographic assays, the peak response related to blank matrix at the RT of analyte should be not more than $20 \%$ of the mean response of the LOQ samples and the peak response at the RT of the IS should be no more than $5 \%$ of the mean peak response of the IS of the LOQ.

\section{Linearity}

The standard curves were linear over the concentration range of 1.0$20.00 \mathrm{ng} / \mathrm{ml}$ of entrectinib Fig. 1. The mean correlation coefficient was 0.999. Samples were quantified using the ratio of peak area of the analyte to that of IS. Peak area ratios were plotted against plasma concentrations. The results are shown in Table 4 and the chromatograms shown in Figs. 8-15.

\section{Development of LCMS method for entrectinib} Acceptance criteria

The criteria for the acceptability of the data include accuracy within $85-115 \%$ from the actual values. No interfering peaks were found

Table 2: System suitability results of entrectinib

\begin{tabular}{lllll}
\hline Sample name & Analyte area & Analyte RT (min) & IS area & IS RT (min) \\
\hline MQC & $3.428 \times 10^{5}$ & 5.226 & $3.485 \times 10^{5}$ & 5.222 \\
MQC & $3.462 \times 10^{5}$ & 5.221 & $3.481 \times 10^{5}$ & 5.236 \\
MQC & $3.479 \times 10^{5}$ & 5.223 & $3.476 \times 10^{5}$ & 5.227 \\
MQC & $3.466 \times 10^{5}$ & 5.227 & $3.449 \times 10^{5}$ & 5.231 \\
MQC & $3.458 \times 10^{5}$ & 5.229 & $3.478 \times 10^{5}$ & 5.235 \\
MQC & $3.487 \times 10^{5}$ & 5.226 & $3.461 \times 10^{5}$ & 5.230 \\
Mean & $3.463 \times 10^{5}$ & 5.225 & $3.474 \times 10^{5}$ & 5.230 \\
SD & 0.02045 & 0.00288 & 0.0198 & 0.0009 \\
\%RSD & 0.59 & 0.06 & 0.62 & 0.00519 \\
\hline
\end{tabular}

Analyte RT (min): Analyte retention time in minutes, IS area: Internal standard area, IS RT (min): Internal standard retention time in minutes 
Table 3: Accuracy and precision of data of the entrectinib $(n=6)$

\begin{tabular}{|c|c|c|c|c|c|}
\hline Quality control sample & Spiked concentration $(\mathrm{ng} / \mathrm{ml})$ & Mean (ng/ml) & SD & Accuracy (\%) & RSD (\%) \\
\hline \multicolumn{6}{|l|}{ Intra-day } \\
\hline LLOQ & $0.3865 \times 10^{5}$ & $0.3841 \times 10^{5}$ & 0.0157 & 96.32 & 0.82 \\
\hline LQC & $1.6724 \times 10^{5}$ & $1.6711 \times 10^{5}$ & 0.0326 & 98.28 & 0.16 \\
\hline MQC & $3.4625 \times 10^{5}$ & $3.4628 \times 10^{5}$ & 0.0458 & 100.05 & 0.33 \\
\hline HQC & $5.0637 \times 10^{5}$ & $5.0664 \times 10^{5}$ & 0.0269 & 99.89 & 0.08 \\
\hline \multicolumn{6}{|l|}{ Inter-day } \\
\hline LLOQ & $0.3851 \times 10^{5}$ & $0.3836 \times 10^{5}$ & 0.0126 & 95.63 & 0.76 \\
\hline MQC & $3.4696 \times 10^{5}$ & $3.4665 \times 10^{5}$ & 0.0428 & 99.58 & 0.26 \\
\hline HQC & $5.061 \times 10^{5}$ & $5.0643 \times 10^{5}$ & 0.0238 & 97.42 & 0.14 \\
\hline
\end{tabular}

SD: Standard deviation, RSD: Relative standard deviation, LLOQ: Lower limit of quality control, LQC: Low-quality control, MQC: Mid quality control, HQC: High-quality control

Table 4: linearity data of entrectinib

\begin{tabular}{|c|c|c|c|c|c|c|c|c|}
\hline Linearity & Plasma $(\mu \mathrm{l})$ & ACN $(\mu \mathrm{l})$ & Std stock $(\mu \mathrm{l})$ & IS $(\mu \mathrm{l})$ & MP added $(\mu l)$ & $\begin{array}{l}\text { Entrectinib concentration } \\
(\mathrm{ng} / \mathrm{ml})\end{array}$ & $\begin{array}{l}\text { Entrectinib } \\
\text { response }\end{array}$ & $\begin{array}{l}\text { Area res } \\
\text { ratio }\end{array}$ \\
\hline Linearity-1 & 200 & 300 & 50 & 500 & 1450 & 1.00 & 0.388 & 0.111 \\
\hline Linearity-2 & 200 & 300 & 125 & 500 & 1375 & 2.50 & 0.849 & 0.244 \\
\hline Linearity-3 & 200 & 300 & 250 & 500 & 1250 & 5.00 & 1.688 & 0.486 \\
\hline Linearity-4 & 200 & 300 & 375 & 500 & 1125 & 7.50 & 2.463 & 0.714 \\
\hline Linearity-5 & 200 & 300 & 500 & 500 & 1000 & 10.00 & 3.429 & 0.986 \\
\hline Linearity-6 & 200 & 300 & 625 & 500 & 875 & 12.50 & 4.163 & 1.203 \\
\hline Linearity-8 & 200 & 300 & 1000 & 500 & 500 & 20.00 & 6.529 & 1.877 \\
\hline Slope & & & & & & 0.0940 & & \\
\hline Intercept & & & & & & 0.01637 & & \\
\hline$r^{2}$ & & & & & & 0.99935 & & \\
\hline
\end{tabular}

ACN: Acetonitrile, std stock: Standard stock, IS: Internal standard, MP added: Mobile phase added

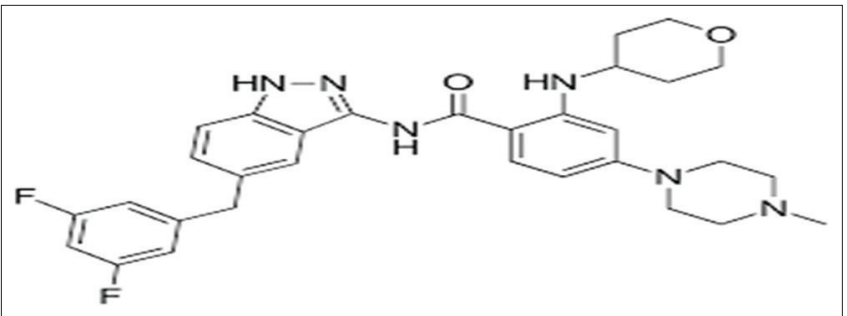

Fig. 1: Structure for entrectinib

in six different random blank rat plasma samples at the RTs of either entrectinib or IS.

\section{Specificity and selectivity}

No interfering peaks were found in six different random blank rat plasma samples at the RTs of either entrectinib or IS.

As observed from the above chromatogram, total run time was $10 \mathrm{~min}$ and the RT of drugs and IS was about 5.211 and $5.214 \mathrm{~min}$, respectively. For blank plasma chromatogram, there were no interfering peaks near the peaks for entrectinib and IS. Same is observed in the case of the chromatogram of blank plasma spiked with IS

\section{Acceptance criteria}

The Linearity Regression coefficient should be $\mathrm{R}^{2}=0.999$

\section{Recovery or extraction efficiency}

Recovery studies are often determined by comparing the detector response of the analyte or IS from an extracted sample to the unextracted samples. Unextracted sample might be a neat drug solution of equivalent concentration. A minimum of six samples at each QC level should be injected [10]. Recovery deemed acceptable if $\% \mathrm{CV}$ is $15 \%$ for $\%$ mean recovery between low, middle, and HQC levels [11]. The results are shown in Table 5.

\section{Sensitivity}

The lowest standard (LOQ) is always accepted as the LOQ of the method. Sensitivity should be evaluated using at least five replicates of the samples at the LOQ. The compliance limits for LOQ should be $\pm 20 \%$ for accuracy and $\leq 20 \%$ for precision [12]. In addition, signal to noise ratio $(\mathrm{S} / \mathrm{N})$ should be at least 5:1. The results are shown in Table 6 .

\section{Matrix effect}

Matrix factor is a way of assessing the matrix effect. Since ionization of analyte is going to be suffering from the presence of endogenous components in the biological matrix, it could be either suppression or enhancement [13].

According to the method peak, response could be peak area, peak height, and peak area ratio or peak height ratio. Matrix factor equal to 1 indicates no matrix effect, matrix factor $<1$ indicates suppression, and $>1$ indicates enhancement [14]. The IS normalized matrix factor (ratio of analyte and IS matrix factor) using stable isotope-labeled IS is generally usually close to unity for the bioanalytical samples. It is recommended that matrix factor or IS normalized matrix factor being determined in six different lots of matrices. The variability in matrix factors as measured by the coefficient of variation $(\% \mathrm{CV})$ should be $<15 \%$. The results are shown in Table 7.

\section{Acceptance criteria}

The \%RSD of recovery at each QC level and for ISTD should be $\leq 15.00 \%$. The overall mean recovery \%RSD for all QC levels should be $\leq 20.00$

\section{Acceptance criteria}

At least $67 \%$ (4 of 6) of samples should be within 80.00-120.00.

\% Mean accuracy should be within $80.00-120.00 \%$. \%RSD accuracy should be $\leq 20.00 \%$.

\section{Acceptance criteria}

At least $67 \%$ (2 of 3) of samples at each level should be within 85.00$115.00 \%$. At least $80 \%$ (5 of 6 ) of the matrix lot should be within 


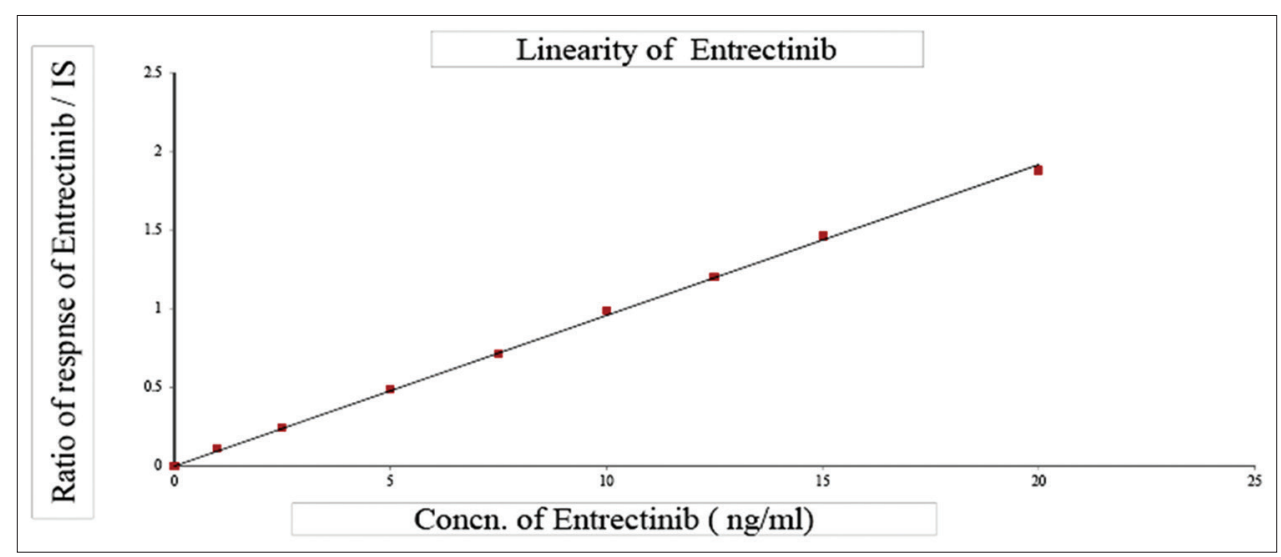

Fig. 2: Calibration curve for entrectinib

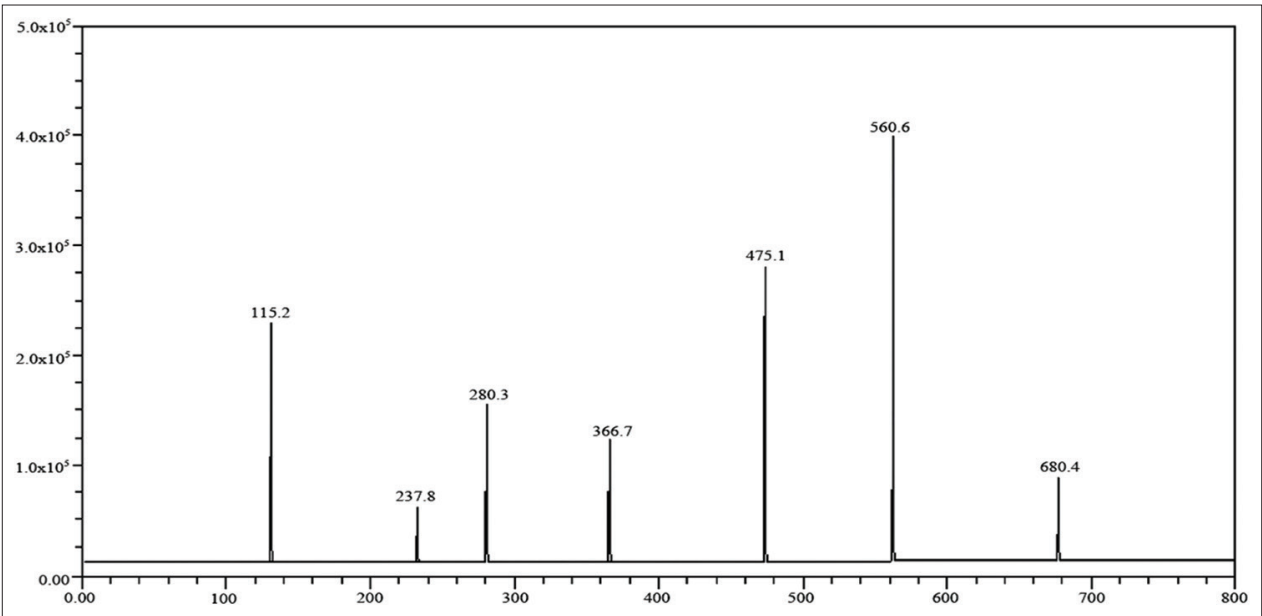

Fig. 3: Mass spectrometry spectra of entrectinib

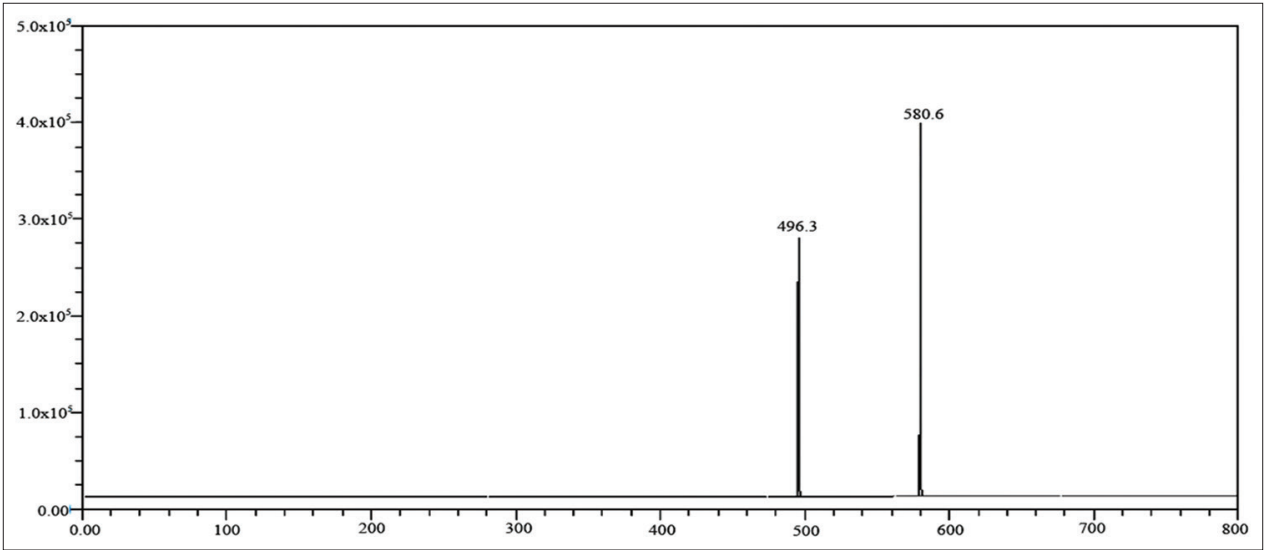

Fig. 4: Mass spectrometry spectra of D4-entrectinib

the acceptance criteria. The \% mean accuracy of back-calculated concentration of LQC and HQC samples prepared from different biological matrix lots should be within $85.00-115.00 \%$.

\section{Stability experiments}

The stability study was evaluated as part of the method validation. To assess the decomposition of the entrectinib that may occur due to different reasons, the following stability test was prepared. The stability tests should reflect the situations likely to be encountered during routine sample handling and analysis [15]. The following stability test was performed.

\section{Freeze-thaw stability}

Six replicates of each (LQC, MQC, and $\mathrm{HQC}$ ) that were stored at $-20^{\circ} \mathrm{C}$ were thawed completely thawing at room temperature and refrozen immediately to $-20^{\circ} \mathrm{C}$. This process was repeated twice and the samples were extracted for injection into LCMS. The results are shown in Table 8.

\section{Benchtop stability}

For benchtop stability experiment, stability of entrectinib in the rat plasma after $8 \mathrm{~h}$ exposure on benchtop was determined at three concentrations (LQC, MQC, and HQC) in six replicates. The results are shown in Table 9 . 


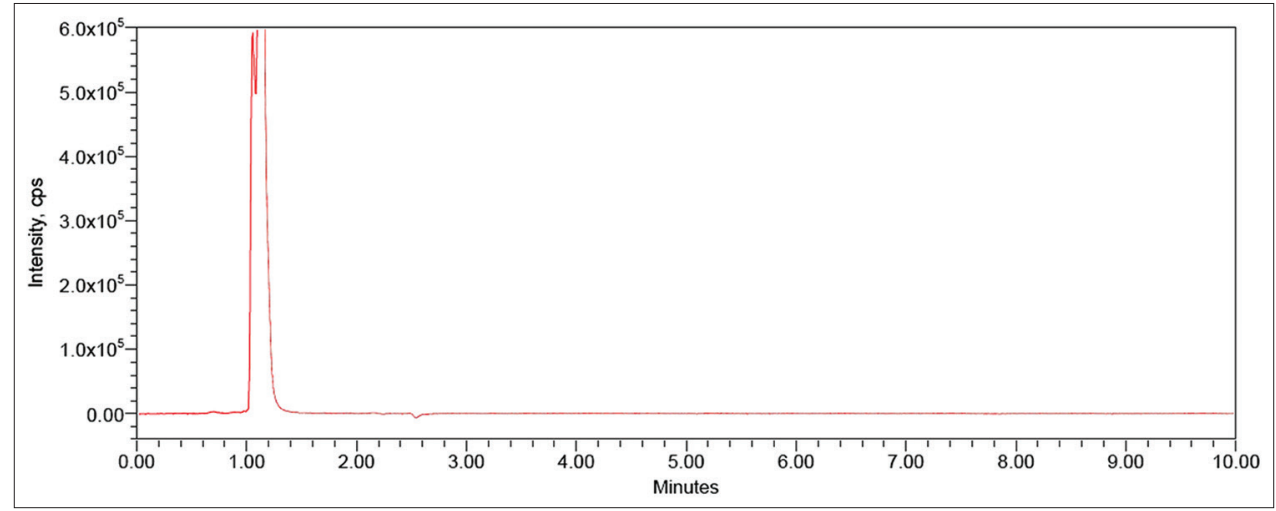

Fig. 5: Blank rat plasma

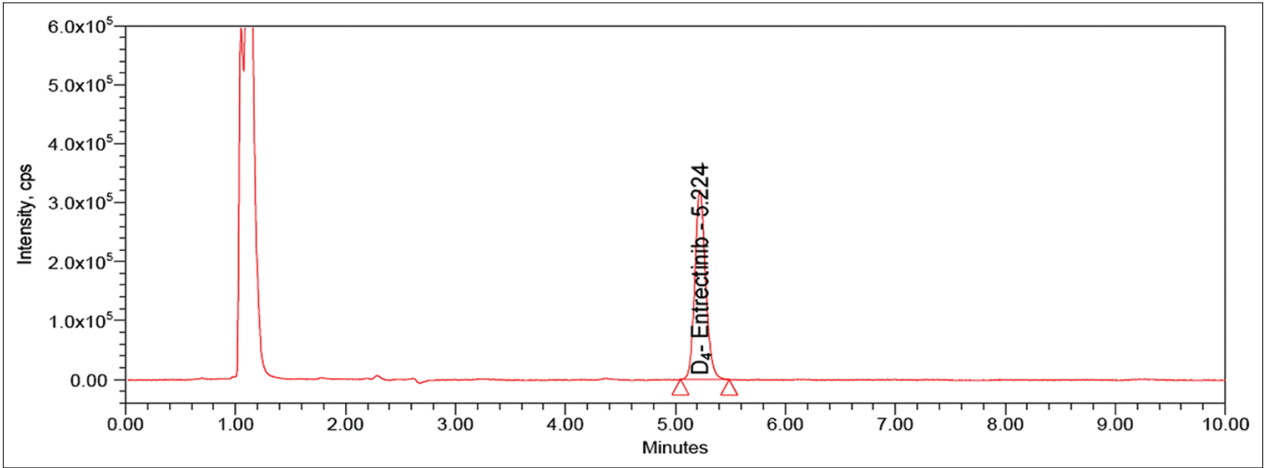

Fig. 6: Blank rat plasma spiked with internal standard

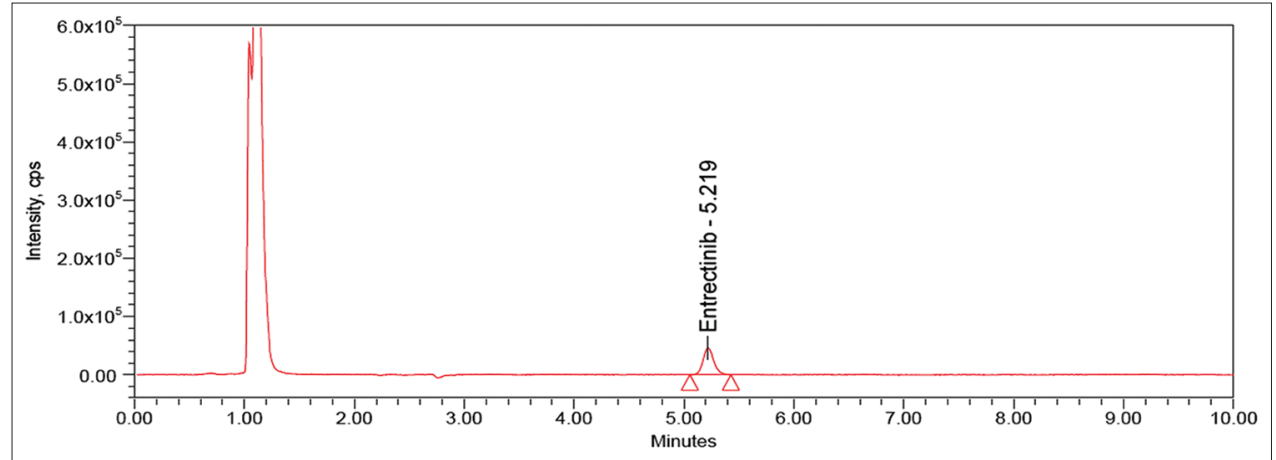

Fig. 7: Blank rat plasma spiked with analyte at a lower limit of quality control and internal standard

Table 5: Recovery of the analyte of entrectinib

\begin{tabular}{|c|c|c|c|c|c|c|}
\hline \multirow[t]{2}{*}{ Replicate number } & \multicolumn{2}{|l|}{ HQC } & \multicolumn{2}{|l|}{ MQC } & \multicolumn{2}{|l|}{ LQC } \\
\hline & $\begin{array}{l}\text { Extracted } \\
\text { response }\end{array}$ & $\begin{array}{l}\text { Unextracted } \\
\text { response }\end{array}$ & $\begin{array}{l}\text { Extracted } \\
\text { response }\end{array}$ & $\begin{array}{l}\text { Unextracted } \\
\text { response }\end{array}$ & $\begin{array}{l}\text { Extracted } \\
\text { response }\end{array}$ & $\begin{array}{l}\text { Unextracted } \\
\text { response }\end{array}$ \\
\hline 1 & $5.056 \times 10^{5}$ & $5.642 \times 10^{5}$ & $3.325 \times 10^{5}$ & $3.859 \times 10^{5}$ & $1.684 \times 10^{5}$ & $2.159 \times 10^{5}$ \\
\hline 2 & $5.064 \times 10^{5}$ & $5.638 \times 10^{5}$ & $3.319 \times 10^{5}$ & $3.847 \times 10^{5}$ & $1.623 \times 10^{5}$ & $2.135 \times 10^{5}$ \\
\hline 3 & $5.068 \times 10^{5}$ & $5.614 \times 10^{5}$ & $3.367 \times 10^{5}$ & $3.863 \times 10^{5}$ & $1.647 \times 10^{5}$ & $2.147 \times 10^{5}$ \\
\hline 4 & $5.055 \times 10^{5}$ & $5.632 \times 10^{5}$ & $3.342 \times 10^{5}$ & $3.824 \times 10^{5}$ & $1.619 \times 10^{5}$ & $2.152 \times 10^{5}$ \\
\hline 5 & $5.047 \times 10^{5}$ & $5.628 \times 10^{5}$ & $3.335 \times 10^{5}$ & $3.855 \times 10^{5}$ & $1.665 \times 10^{5}$ & $2.133 \times 10^{5}$ \\
\hline 6 & $5.062 \times 10^{5}$ & $5.629 \times 10^{5}$ & $3.371 \times 10^{5}$ & $3.829 \times 10^{5}$ & $1.634 \times 10^{5}$ & $2.124 \times 10^{5}$ \\
\hline $\mathrm{n}$ & 6 & 6 & 6 & 6 & 6 & 6 \\
\hline Mean & $5.059 \times 10^{5}$ & $5.631 \times 10^{5}$ & $3.343 \times 10^{5}$ & $3.846 \times 10^{5}$ & $1.645 \times 10^{5}$ & $2.142 \times 10^{5}$ \\
\hline SD & 0.00753 & 0.00971 & 0.02156 & 0.01620 & 0.02532 & 0.01317 \\
\hline$\%$ RSD & 0.15 & 0.17 & 0.63 & 0.42 & 1.54 & 0.61 \\
\hline \%Mean Recovery & 96.72 & $101.22 \%$ & $95.87 \%$ & $101.47 \%$ & $94.35 \%$ & $100.01 \%$ \\
\hline Overall \% Mean Recovery & $98.27 \%$ & & & & & \\
\hline Overall SD & 3.0167 & & & & & \\
\hline
\end{tabular}

SD: Standard deviation, RSD: Relative standard deviation, LQC: Low-quality control, MQC: Mid quality control, HQC: High-quality control, SD: Standard deviation, RSD: Relative standard deviation, 


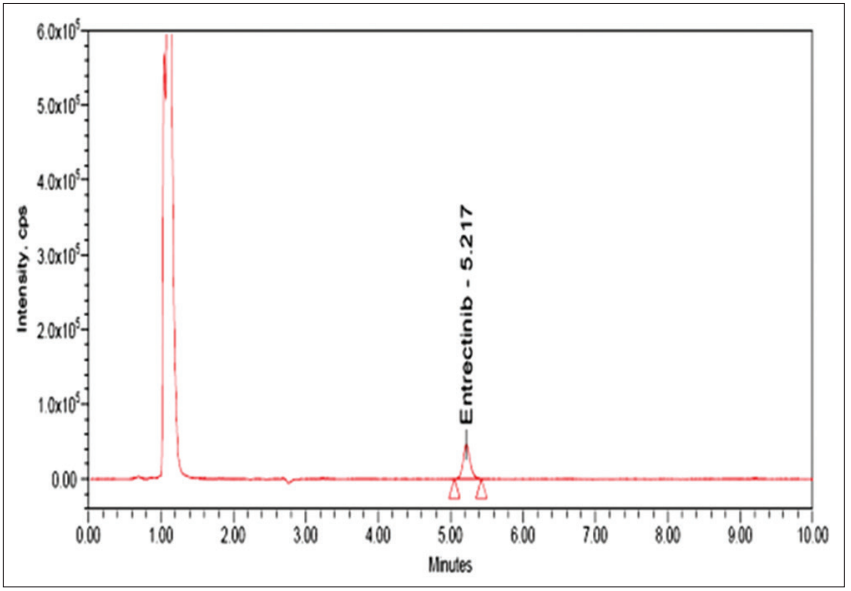

Fig. 8: Chromatogram for linearity-1

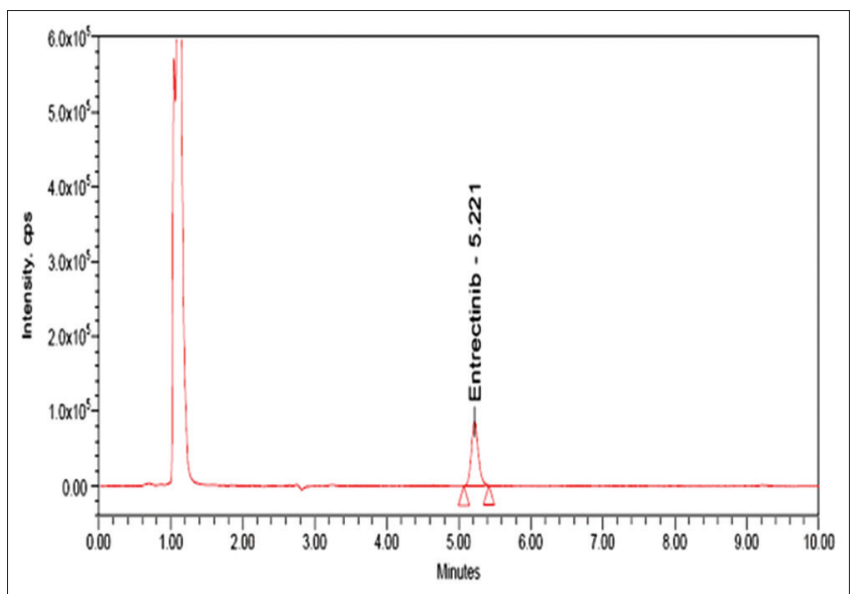

Fig. 9: Chromatogram for linearity-2

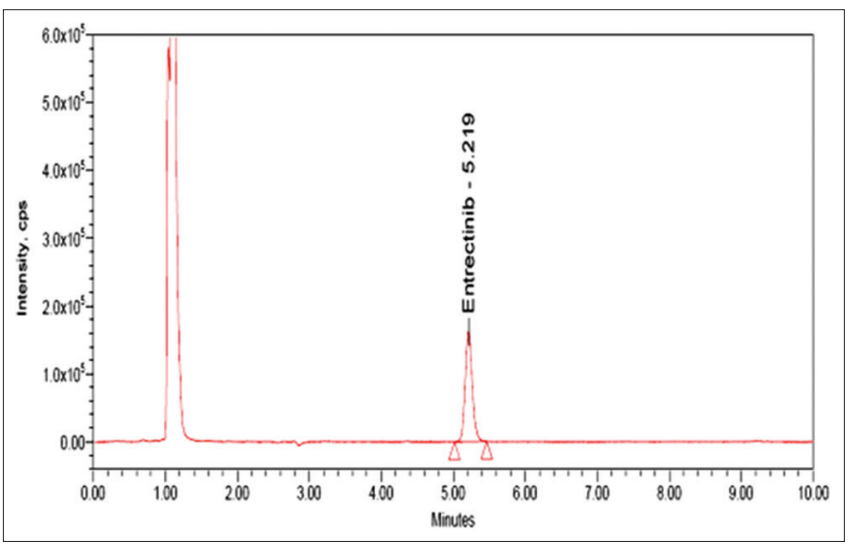

Fig. 10: Chromatogram for linearity-3

\section{Wet extract stability}

Freezer stability of entrectinib in plasma was assessed by analyzing LQC, $\mathrm{MQC}$, and $\mathrm{HQC}$ samples in six replicates stored at $-20^{\circ} \mathrm{C}$ for $24 \mathrm{~h}$ for the stability study. All samples compared with the fresh prepare samples of three different QC in six replicates. Samples were considered to be stable if assay values were in compliance with the acceptable limits of accuracy (i.e., $\pm 15 \%$ SD) and precision (i.e., $\pm 15 \%$ RSD; Food and Drug Administration of the United States, 2001). The results are shown in Table 10.

\section{Auto sampler stability}

Samples of entrectinib in plasma were assessed by analyzing LQC, MQC, and HQC samples are injected every $1 \mathrm{~h}$ up to $24 \mathrm{~h}$ for the stability

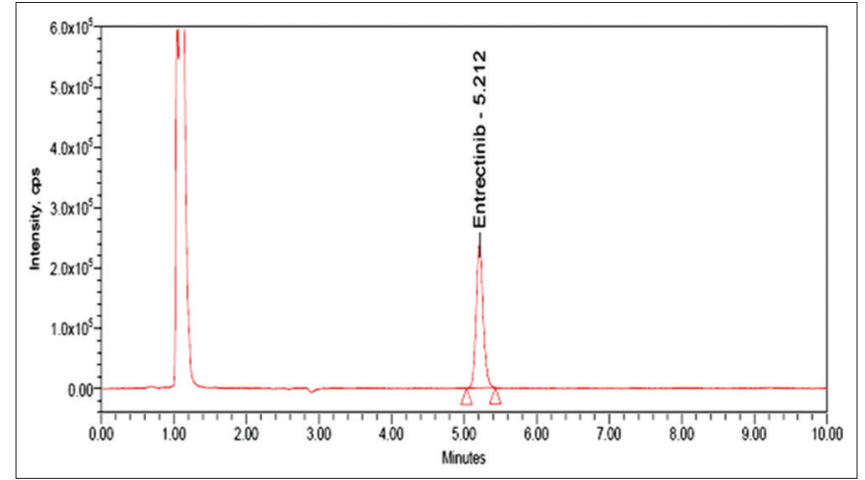

Fig. 11: Chromatogram for linearity-4

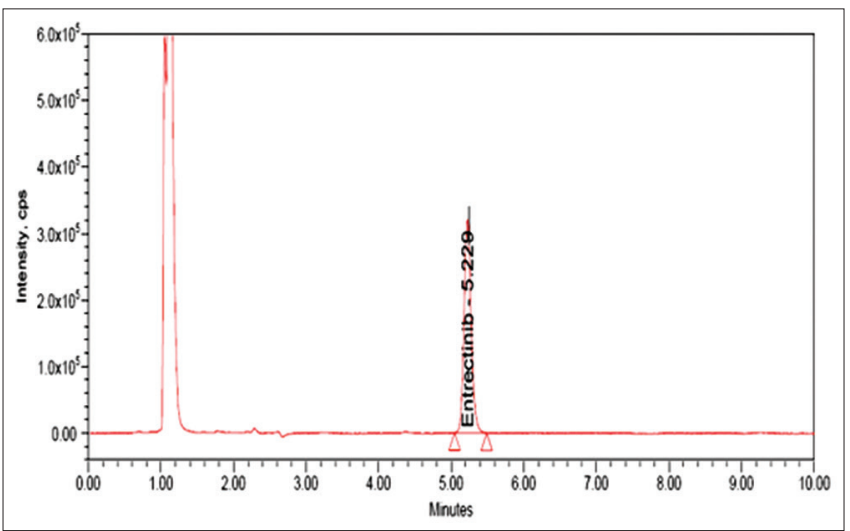

Fig. 12: Chromatogram for linearity-5

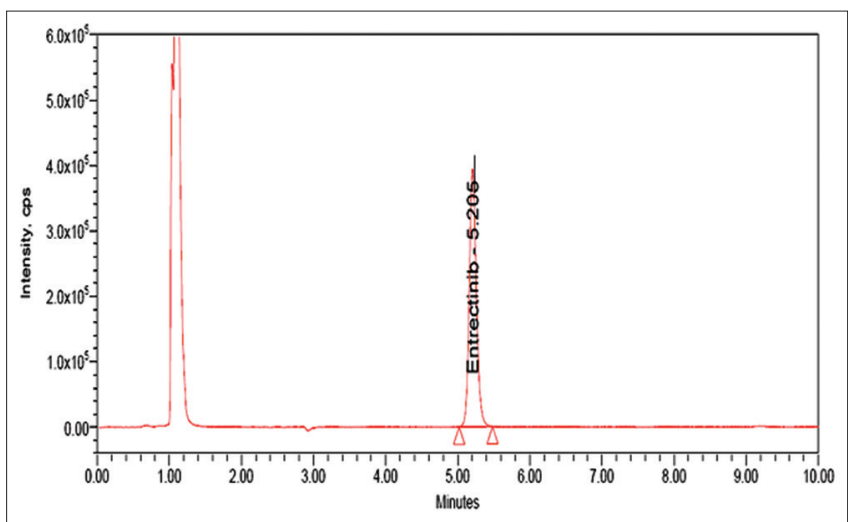

Fig. 13: Chromatogram for linearity-6

study. All samples compared with the fresh prepare samples of $0 \mathrm{Hr}$ of different QC in six replicates. Samples were considered to be stable if assay values meet the compliance with the acceptable limits of accuracy (i.e., $\pm 15 \%$ SD) and precision (i.e., $\pm 15 \%$ RSD; Food and Drug Administration of the United States, 2001). The results are shown in Table 11.

\section{Long-term stability studies}

Long-term stability was also performed at day 1 , day 7 , day 14 , day 21 , and day 28 . The percentage mean accuracy was within limits $(85-115 \%)$. These values indicating that entrectinib is stable for 28 days.

\section{Freeze thaw at $-80^{\circ} \mathrm{C}$}

The $\%$ RSD and mean accuracy for entrectinib were found to be $0.28 \%$, $96.60 \%$ and $0.70 \%, 94.25 \%$ and $0.30 \%$, and $98.72 \%$. Hence it passed the Freeze-thaw at $-80^{\circ} \mathrm{C}$. 
Table 6: Sensitivity results of entrectinib

\begin{tabular}{ll}
\hline $\begin{array}{l}\text { Replicate } \\
\text { number }\end{array}$ & LLOQ \\
\cline { 2 - 2 } & Nominal concentration $\mathbf{n g} / \mathbf{m l})$ \\
\cline { 2 - 2 } & $\mathbf{1 . 1 5 4}$ \\
\cline { 2 - 2 } & Nominal concentration range $\mathbf{n g} / \mathbf{m l})$ \\
\cline { 2 - 2 } & $\mathbf{( 1 . 0 2 3 - 1 . 2 4 1 )}$ \\
\cline { 2 - 2 } & Area $\mathbf{0 f}$ Analyte \\
\hline 1 & $0.342 \times 10^{5}$ \\
3 & $0.336 \times 10^{5}$ \\
4 & $0.357 \times 105$ \\
5 & $0.312 \times 105$ \\
6 & $0.328 \times 105$ \\
N & $0.364 \times 105$ \\
Mean & 6 \\
SD & $0.340 \times 105$ \\
$\%$ RSD & 0.01904 \\
$\%$ mean accuracy & 5.6 \\
\hline
\end{tabular}

LLOQ: Lower limit of quality control, SD: Standard deviation, RSD: Relative standard deviation

Table 7: Matrix effect results of entrectinib

\begin{tabular}{|c|c|c|c|}
\hline \multirow[t]{6}{*}{ S. no. } & \multirow{6}{*}{$\begin{array}{l}\text { Plasma } \\
\text { lot no. }\end{array}$} & HQC & LQC \\
\hline & & \multicolumn{2}{|c|}{ Nominal concentration $(\mathrm{ng} / \mathrm{ml})$} \\
\hline & & 15.341 & 5.369 \\
\hline & & \multicolumn{2}{|c|}{ Nominal concentration range $(\mathrm{ng} / \mathrm{ml})$} \\
\hline & & $(15.269-15.517)$ & $(5.206-5.578)$ \\
\hline & & \multicolumn{2}{|c|}{ Calculated concentration (ng/ml) } \\
\hline \multirow[t]{3}{*}{1.} & Lot 1 & $5.056 \times 10^{5}$ & $1.683 \times 10^{5}$ \\
\hline & & $5.047 \times 10^{5}$ & $1.657 \times 10^{5}$ \\
\hline & & $5.052 \times 10^{5}$ & $1.658 \times 10^{5}$ \\
\hline \multirow[t]{3}{*}{2.} & Lot 2 & $5.055 \times 10^{5}$ & $1.625 \times 10^{5}$ \\
\hline & & $5.026 \times 10^{5}$ & $1.556 \times 10^{5}$ \\
\hline & & $5.047 \times 10^{5}$ & $1.586 \times 10^{5}$ \\
\hline \multirow[t]{3}{*}{3.} & Lot 3 & $5.033 \times 10^{5}$ & $1.574 \times 10^{5}$ \\
\hline & & $5.029 \times 10^{5}$ & $1.536 \times 10^{5}$ \\
\hline & & $5.026 \times 10^{5}$ & $1.527 \times 10^{5}$ \\
\hline \multirow[t]{3}{*}{4.} & Lot 4 & $5.038 \times 10^{5}$ & $1.529 \times 10^{5}$ \\
\hline & & $5.047 \times 10^{5}$ & $1.533 \times 10^{5}$ \\
\hline & & $5.022 \times 10^{5}$ & $1.547 \times 10^{5}$ \\
\hline \multirow[t]{3}{*}{5.} & Lot 5 & $5.057 \times 10^{5}$ & $1.549 \times 10^{5}$ \\
\hline & & $5.053 \times 10^{5}$ & $1.558 \times 10^{5}$ \\
\hline & & $5.022 \times 10^{5}$ & $1.542 \times 10^{5}$ \\
\hline \multirow[t]{3}{*}{6.} & Lot 6 & $5.036 \times 10^{5}$ & $1.531 \times 10^{5}$ \\
\hline & & $5.018 \times 10^{5}$ & $1.574 \times 10^{5}$ \\
\hline & & $5.045 \times 10^{5}$ & $1.529 \times 10^{5}$ \\
\hline \multicolumn{2}{|l|}{$\mathrm{N}$} & 18 & 18 \\
\hline \multicolumn{2}{|l|}{ Mean } & $5.039 \times 10^{5}$ & $1.572 \times 10^{5}$ \\
\hline \multicolumn{2}{|l|}{ SD } & 0.01320 & 0.05011 \\
\hline \multicolumn{2}{|l|}{$\% \mathrm{CV}$} & 0.26 & 3.19 \\
\hline \multicolumn{2}{|c|}{$\%$ mean accuracy } & $97.01 \%$ & $90.81 \%$ \\
\hline \multicolumn{2}{|c|}{ No. of QC failed } & 0 & 0 \\
\hline \multicolumn{4}{|c|}{$\begin{array}{l}\text { HQC: High-quality control, LQC: Low-quality control, N: Number of samples, } \\
\text { SD: Standard deviation, CV: Coefficient of variation }\end{array}$} \\
\hline \multicolumn{4}{|c|}{ Benchtop stability } \\
\hline \multicolumn{4}{|c|}{$\begin{array}{l}\text { The } \% \text { CV of } \mathrm{HQC}, \mathrm{LQC} \text {, and MQC mean accuracy for entrectinib was } \\
\text { found to be } 0.24 \%, 0.67 \% \text {, and } 0.23 \% \text {. Hence, it passed the benchtop } \\
\text { stability. }\end{array}$} \\
\hline
\end{tabular}

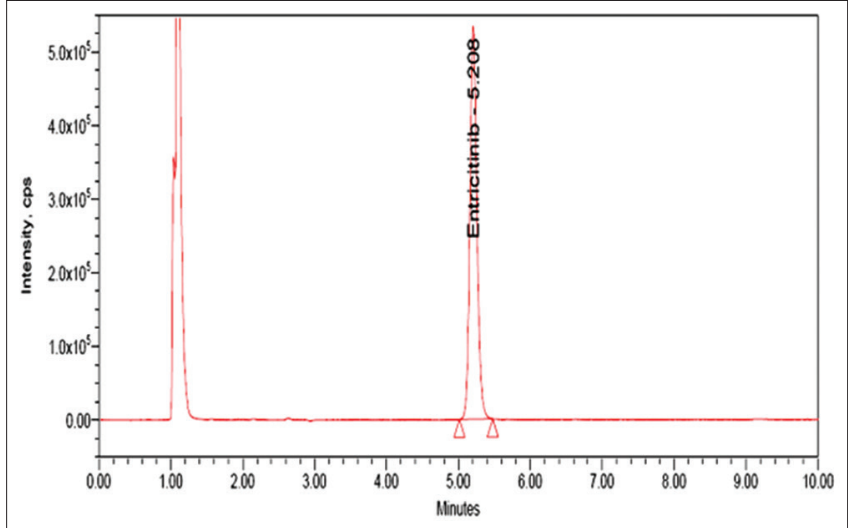

Fig. 14: Chromatogram for linearity-7

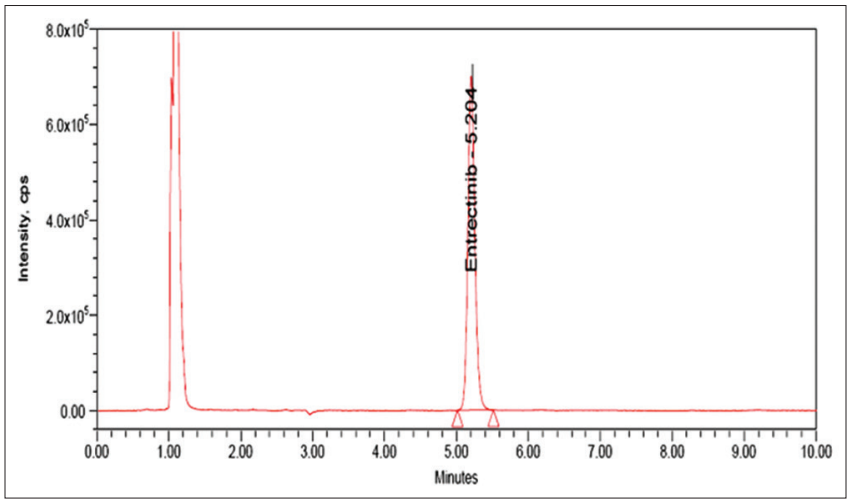

Fig. 15: Chromatogram for linearity-8

Table 8: Freeze-thaw at $-80^{\circ} \mathrm{C}$ of entrectinib

\begin{tabular}{|c|c|c|c|}
\hline \multirow{6}{*}{$\begin{array}{l}\text { Replicate } \\
\text { no. }\end{array}$} & HQC & LQC & MQC \\
\hline & \multicolumn{3}{|c|}{ Nominal concentration $(\mathrm{ng} / \mathrm{ml})$} \\
\hline & 15.269 & 5.127 & 10.154 \\
\hline & \multicolumn{3}{|c|}{ Nominal concentration range $(\mathrm{ng} / \mathrm{ml})$} \\
\hline & $(15.2128-15.369)$ & $(5.028-5.260)$ & $(10.022-10.254)$ \\
\hline & \multicolumn{3}{|l|}{ Analyte peak area } \\
\hline 1 & $5.029 \times 10^{5}$ & $1.635 \times 10^{5}$ & $3.415 \times 10^{5}$ \\
\hline 2 & $5.005 \times 10^{5}$ & $1.628 \times 10^{5}$ & $3.417 \times 10^{5}$ \\
\hline 3 & $5.014 \times 10^{5}$ & $1.642 \times 10^{5}$ & $3.425 \times 10^{5}$ \\
\hline 4 & $5.003 \times 10^{5}$ & $1.611 \times 10^{5}$ & $3.436 \times 10^{5}$ \\
\hline 5 & $5.017 \times 10^{5}$ & $1.641 \times 10^{5}$ & $3.412 \times 10^{5}$ \\
\hline 6 & $5.039 \times 10^{5}$ & $1.632 \times 10^{5}$ & $3.408 \times 10^{5}$ \\
\hline $\mathrm{N}$ & 6 & 6 & 6 \\
\hline Mean & $5.018 \times 10^{5}$ & $1.632 \times 10^{5}$ & $3.419 \times 10^{5}$ \\
\hline SD & 0.01395 & 0.01136 & 0.01015 \\
\hline$\% \mathrm{CV}$ & 0.28 & 0.70 & 0.30 \\
\hline $\begin{array}{l}\% \text { mean } \\
\text { accuracy }\end{array}$ & $96.60 \%$ & $94.25 \%$ & $98.72 \%$ \\
\hline
\end{tabular}

\section{Wet extract}

The $\%$ RSD and mean accuracy for entrectinib were found to be $0.34 \%$, $97.14 \%$ and $1.33 \%, 95.58 \%$ and $0.59 \%$, and $99.97 \%$. Hence, it passed the wet extract at $-28^{\circ} \mathrm{C}$. 
Table 9: Benchtop stability of entrectinib

\begin{tabular}{|c|c|c|c|}
\hline \multirow{6}{*}{$\begin{array}{l}\text { Replicate } \\
\text { no. }\end{array}$} & HQC & LQC & MQC \\
\hline & \multicolumn{3}{|c|}{ Nominal concentration $(\mathrm{ng} / \mathrm{ml})$} \\
\hline & 15.364 & 5.287 & 10.157 \\
\hline & \multicolumn{3}{|c|}{ Nominal concentration range $(\mathrm{ng} / \mathrm{ml})$} \\
\hline & $(15158-15.462)$ & $(5.036-5.369)$ & $(10.017-10.239)$ \\
\hline & \multicolumn{3}{|l|}{ Analyte peak area } \\
\hline 1 & $5.016 \times 10^{5}$ & $1.647 \times 10^{5}$ & $3.415 \times 10^{5}$ \\
\hline 2 & $5.019 \times 10^{5}$ & $1.628 \times 10^{5}$ & $3.418 \times 10^{5}$ \\
\hline 3 & $5.021 \times 10^{5}$ & $1.637 \times 10^{5}$ & $3.422 \times 10^{5}$ \\
\hline 4 & $5.048 \times 10^{5}$ & $1.629 \times 10^{5}$ & $3.407 \times 10^{5}$ \\
\hline 5 & $5.017 \times 10^{5}$ & $1.645 \times 10^{5}$ & $3.402 \times 10^{5}$ \\
\hline 6 & $5.029 \times 10^{5}$ & $1.656 \times 10^{5}$ & $3.406 \times 10^{5}$ \\
\hline $\mathrm{N}$ & 6 & 6 & 6 \\
\hline Mean & $5.025 \times 10^{5}$ & $1.64 \times 10^{5}$ & $3.412 \times 10^{5}$ \\
\hline SD & 0.01218 & 0.01098 & 0.00781 \\
\hline$\% \mathrm{CV}$ & 0.24 & 0.67 & 0.23 \\
\hline $\begin{array}{l}\% \text { mean } \\
\text { accuracy }\end{array}$ & $96.73 \%$ & $94.71 \%$ & $98.53 \%$ \\
\hline
\end{tabular}

LQC: Low-quality control, MQC: Mid quality control, HQC: High-quality control, $\mathrm{N}$ : Number of samples, SD: Standard deviation, CV: Coefficient of variation

Table 10: Wet extract stability of entrectinib

\begin{tabular}{|c|c|c|c|}
\hline \multirow{6}{*}{$\begin{array}{l}\text { Replicate } \\
\text { no. }\end{array}$} & HQC & LQC & MQC \\
\hline & \multicolumn{3}{|c|}{ Nominal concentration (ng/ml) } \\
\hline & 15.247 & 5.298 & 10.356 \\
\hline & \multicolumn{3}{|c|}{ Nominal concentration range $(\mathrm{ng} / \mathrm{ml})$} \\
\hline & (15.142-15.336) & $(5.167-5.374)$ & (10.247-10.464) \\
\hline & \multicolumn{3}{|l|}{ Analyte peak area } \\
\hline 1 & $5.029 \times 10^{5}$ & $1.654 \times 10^{5}$ & $3.465 \times 10^{5}$ \\
\hline 2 & $5.067 \times 10^{5}$ & $1.654 \times 10^{5}$ & $3.487 \times 10^{5}$ \\
\hline 3 & $5.027 \times 10^{5}$ & $1.629 \times 10^{5}$ & $3.462 \times 10^{5}$ \\
\hline 4 & $5.064 \times 10^{5}$ & $1.634 \times 10^{5}$ & $3.477 \times 10^{5}$ \\
\hline 5 & $5.038 \times 10^{5}$ & $1.678 \times 10^{5}$ & $3.429 \times 10^{5}$ \\
\hline 6 & $5.049 \times 10^{5}$ & $1.683 \times 10^{5}$ & $3.451 \times 10^{5}$ \\
\hline $\mathrm{N}$ & 6 & 6 & 6 \\
\hline Mean & $5.046 \times 10^{5}$ & $1.655 \times 10^{5}$ & $3.462 \times 10^{5}$ \\
\hline SD & 0.01725 & 0.02205 & 0.02034 \\
\hline$\% \mathrm{CV}$ & 0.34 & 1.33 & 0.59 \\
\hline$\%$ Mean & $97.14 \%$ & $95.58 \%$ & $99.97 \%$ \\
\hline Accuracy & & & \\
\hline
\end{tabular}

LQC: Low-quality control, MQC: Mid quality control, HQC: High-quality control, N: Number of samples, SD: Standard deviation, CV: Coefficient of variation

\section{Auto sampler stability}

The $\%$ RSD and mean accuracy for entrectinib were found to be $0.42 \%$, $0.78 \%$, and 1.40 . Hence, it passed the autosampler stability.

\section{CONCLUSION}

A bioanalytical LC-MS/MS method for the entrectinib was developed and validated with entrectinib $\mathrm{D}_{4}$ as IS. The method has excellent accuracy, precision, and recovery compared with existed methods for the analysis of drug in rat plasma. The methods developed in our laboratory are very simple, utilizing liquid-liquid extraction procedure, which makes the method high throughput for analysis. Entrectinib was eluted within 6 min using RP-high-performance liquid chromatography Luna, $250 \times 4.6 \mathrm{~mm}, 5 \mu \mathrm{m}$ column and the mobile phase containing $0.1 \%$ formic acid and ACN in the ratio of $70: 30 \% \mathrm{v} / \mathrm{v}$ and flow rate was $1.0 \mathrm{ml} / \mathrm{min}$. All the validation data were met the range acceptance criteria of the USFDA guideline.
Table 11: Autosampler stability results of entrectinib

\begin{tabular}{|c|c|c|c|}
\hline \multirow{6}{*}{$\begin{array}{l}\text { Replicate } \\
\text { no. }\end{array}$} & HQC & MQC & LQC \\
\hline & \multicolumn{3}{|c|}{ Nominal concentration $(\mathrm{ng} / \mathrm{ml})$} \\
\hline & 15.315 & 10.452 & 5.526 \\
\hline & \multicolumn{3}{|c|}{ Nominal concentration range $(\mathrm{ng} / \mathrm{ml})$} \\
\hline & $(15.205-15.468)$ & $(10.312-10.629)$ & $(5.387-5.748)$ \\
\hline & \multicolumn{3}{|l|}{ Area of analyte } \\
\hline 1 & $5.026 \times 10^{5}$ & $3.487 \times 10^{5}$ & $1.652 \times 10^{5}$ \\
\hline 2 & $5.039 \times 10^{5}$ & $3.425 \times 10^{5}$ & $1.635 \times 10^{5}$ \\
\hline 3 & $5.027 \times 10^{5}$ & $3.469 \times 10^{5}$ & $1.642 \times 10^{5}$ \\
\hline 4 & $5.018 \times 10^{5}$ & $3.427 \times 10^{5}$ & $1.685 \times 10^{5}$ \\
\hline 5 & $5.029 \times 10^{5}$ & $3.482 \times 10^{5}$ & $1.625 \times 10^{5}$ \\
\hline 6 & $5.044 \times 10^{5}$ & $3.415 \times 10^{5}$ & $1.641 \times 10^{5}$ \\
\hline 7 & $5.052 \times 10^{5}$ & $3.469 \times 10^{5}$ & $1.687 \times 10^{5}$ \\
\hline 8 & $5.058 \times 10^{5}$ & $3.451 \times 10^{5}$ & $1.633 \times 10^{5}$ \\
\hline 9 & $5.067 \times 10^{5}$ & $3.496 \times 10^{5}$ & $1.685 \times 10^{5}$ \\
\hline 10 & $5.062 \times 10^{5}$ & $3.421 \times 10^{5}$ & $1.624 \times 10^{5}$ \\
\hline 11 & $5.039 \times 10^{5}$ & $3.428 \times 10^{5}$ & $1.642 \times 10^{5}$ \\
\hline 12 & $5.027 \times 10^{5}$ & $3.496 \times 10^{5}$ & $1.625 \times 10^{5}$ \\
\hline 13 & $5.068 \times 10^{5}$ & $3.471 \times 10^{5}$ & $1.654 \times 10^{5}$ \\
\hline 14 & $5.047 \times 10^{5}$ & $3.485 \times 10^{5}$ & $1.624 \times 10^{5}$ \\
\hline 15 & $5.085 \times 10^{5}$ & $3.462 \times 10^{5}$ & $1.635 \times 10^{5}$ \\
\hline 16 & $5.069 \times 10^{5}$ & $3.451 \times 10^{5}$ & $1.639 \times 10^{5}$ \\
\hline 17 & $5.067 \times 10^{5}$ & $3.463 \times 10^{5}$ & $1.626 \times 10^{5}$ \\
\hline 18 & $5.064 \times 10^{5}$ & $3.481 \times 10^{5}$ & $1.643 \times 10^{5}$ \\
\hline 19 & $5.074 \times 10^{5}$ & $3.496 \times 10^{5}$ & $1.675 \times 10^{5}$ \\
\hline 20 & $5.078 \times 10^{5}$ & $3.465 \times 10^{5}$ & $1.684 \times 10^{5}$ \\
\hline 21 & $5.095 \times 10^{5}$ & $3.472 \times 10^{5}$ & $1.692 \times 10^{5}$ \\
\hline 22 & $5.082 \times 10^{5}$ & $3.436 \times 10^{5}$ & $1.637 \times 10^{5}$ \\
\hline 23 & $5.061 \times 10^{5}$ & $3.428 \times 10^{5}$ & $1.629 \times 10^{5}$ \\
\hline 24 & $5.072 \times 10^{5}$ & $3.419 \times 10^{5}$ & $1.651 \times 10^{5}$ \\
\hline $\mathrm{N}$ & 24 & 24 & 24 \\
\hline Mean & $5.056 \times 10^{5}$ & $3.458 \times 10^{5}$ & $1.649 \times 10^{5}$ \\
\hline SD & 0.02122 & 0.02709 & 0.02307 \\
\hline$\%$ RSD & 0.42 & 0.78 & 1.40 \\
\hline $\begin{array}{l}\% \text { mean } \\
\text { accuracy }\end{array}$ & $97.3 \%$ & $99.9 \%$ & $95.23 \%$ \\
\hline
\end{tabular}

LQC: Low-quality control, MQC: Mid quality control, HQC: High-quality control, $\mathrm{n}$ : Number of samples, SD: Standard deviation, RSD: Relative standard deviation

\section{REFERENCES}

1. Almeida AM, Castel-Branco MM, Falcao AC. Linear regression for calibration lines revisited, weighting schemes for bioanalytical methods. J Chromatogra B 2002;774:215-22.

2. Available from: https://www.drugbank.ca/drugs/DB11986.

3. Available from: https://www.accessdata.fda.gov/drugsatfda docs/ label/2019/212725s0001bl.pdf.

4. Udhayavani S, Sastry VG, Rajan RG, Krishna VR, Tejaswi JK. One step quantification analytical method and characterization of valsartan by LC-MS. Int J App Pharm 2018;10:108-11.

5. Food and Drug Administration, Center for Drug Evaluation and Research. Guidance for industry, Bionalytical Method Validation. United States: Food and Drug Administration. Center for Drug Evaluation and Research; 2001.

6. Jemal M, Xia YQ. LC-MS development strategies for quantitative bioanalysis. Curr Drug Metab 2006;7:491-502.

7. Kole PL, Venkatesh G, Kotecha J, Sheshala R. Recent advances in sample preparation techniques for effective bioanalytical methods. Biomed Chromatogr 2011;25:199-217.

8. LC-MS/MS Hardware Manuals for API3000 and API4000.

9. Hartmann C, Smeyers-Verbeke J, Massart DL, McDowall RD. Validation of bioanalytical chromatographic methods. J Pharm Biomed Anal 1998; 17:193-218

10. Rao GR, Murthy SS, Khadgapathi P. High performance liquid chromatography and its role in pharmaceutical analysis (review). East Pharm 1986;29:53.

11. Devanshu S, Rahul M, Annu G, Kishan S, Anroop N. Quantitative bioanalysis by LC-MS/MS, a review. J Pharm Biomed Sci 2010;7:1-7.

12. Prasad PB, Satyanarayana K, Mohan GK. Simultaneous 
determination of metformin, linagliptin in jentadueto and metformin, saxagliptin in kombiglyze by LC-MS method. Int J Pharm Pharm Sci 2018;10:110-6.

13. Viswanathan CT, Bansal S, Booth B, DeStefano AJ, Rose MJ, Sailstad J, et al. Quantitative bioanalytical methods validation and implementation, best practices for chromatographic and ligand binding assays. AAPS J 2007;24:1962-73.

14. Shah VP. The history of bioanalytical method validation and regulation, evolution of a guidance document on bioanalytical methods validation. AAPS J 2007;9:E43-7.

15. Willard HH, Merrit LL Jr., Dean JA, Settle FA Jr. Instrumental Methods of Analysis. $6^{\text {th }}$ ed. New Delhi, India: CBS Publishers; 1999. 